\title{
Journal of

\section{The Influence of Building Structure on Human Perception in Interior Spaces}

\author{
Sardar S. Shareef ${ }^{1, * i D}$, Hozan L. Rauf ${ }^{1}$ iD \\ ${ }^{1}$ Architectural Engineering Department,. Faculty of Engineering, Tishk International University-Sulaimani, Sulaimani, 46001, Iraq \\ *Corresponding Author: Sardar S. Shareef, E-mail: sardar.shareef@tiu.edu.iq
}

\begin{tabular}{ll}
\hline Article Info & Abstract \\
\hline Article History & $\begin{array}{l}\text { Structures create interior spaces. However, the sense of every space depends on the type of struc- } \\
\text { ture used. This paper tries to evaluate structural systems apply in architecture and then analyse } \\
\text { Received Jul 30, 2021 }\end{array}$ \\
$\begin{array}{l}\text { space identity given by different structures. The method of this study mainly depends on a survey } \\
\text { in the current literature and case study which the colour building in the department of architecture }\end{array}$ \\
$\begin{array}{l}\text { Accepted Aug 23, 2021 } \\
\text { Keywords }\end{array}$ & in EMU-North Cyprus has taken as the case study. Frame concrete (column and beam) is used in \\
$\begin{array}{l}\text { Architecture structures } \\
\text { Colour }\end{array}$ & the building, which has made the interiors compacted in the structure's boundary. At the same \\
$\begin{array}{l}\text { Perception } \\
\text { Space }\end{array}$ & proliferates visual focal points, corners and angles, to the main space. These visual definitions \\
Space-divisions & lately make the spaces to be more defined.
\end{tabular}

Copyright: (C) 2021 EngiSciece Publisher All rights reserved

\section{Introduction}

Most of human life is spent in interiors, which are designing by human her/himself. Every interior depends on a kind of structure to have existed. This structure offers the interiors a specific definition by the nature of the structure. For instance, human beings impossibly have the same sense in a tent and a frame structure type. For that, every structure that produces a space gives it a specific definition, which goes to have an identity. Sometimes, some goals in terms of identity only are fulfilled by applying a definite structure as an extended huge space is difficult to construct with post and beam, for example. In contrast, it can be easily shaped by a pneumatic structure type.

For that, this paper intends to concentrate on different space definitions by structural systems. Also, analysing different structures from an architectural viewpoint, then evaluating what sense humans may have or how these structural systems give the sense of interiority to the spaces. This interiority "can be defined as a process within a person that reflects an individual's unique awareness of the world and a psychological relationship to the world that is meaningful in ways specific to individual consciousness" [1].

There is a lack of knowledge on how structural systems have an impact on human perception in interior spaces. So, this paper aims to analyse different structural systems and identify their effects on space identity in interiors. 


\section{Literature Review}

Many definitions could be found for the term structure. However, this definition seems to give a logical sense to understand it, as stated in dictionary.com "a complex system considered from the point of view of the whole rather than of any single part". From this definition, we can understand that structure is simple support and a complex system in the broader organisation. As observed in all creatures' bodies, structural systems have collected other parts to give them an identity and speciality. For example, the spine and bones constitute the body shape by holding the whole body in the human body. This structural system acts as an internal core. In crustacean animals, the system of the structure is an outer shell.

In the same way, the structure is most prominent in architecture. It is the base idea to give the architecture identity. Interior spaces are not detached in this effect. For that, structural systems are influencing interior spaces in terms of spatial identities. "As soon as a structure turns a space into a human-scale space, that space becomes a part of our personal world" [2]. That is why structures need to be architected before they provide a 3D form.

According to different specifications and materials, there are several classifications for structural systems, but an architectural organisation for types of structural systems will be discussed below.

- Post and Lintel: This type of structure considers as one of the oldest systems which belong to prehistoric times [3]. This structure is made of posts that are vertical members and beams which horizontally lay on the posts. From the very beginning, both of the vertical and horizontal members were stones. While after that, the Greeks had changed the beams from stone to wood to provide more interior space with less support. Wood has lightweight, and it is less brittle than stone.

Interiors of ancient Egyptians, Romans and Greeks were primarily designed with posts and beams from the very early ages. Buildings are designed to be monumental from the outside, while a huge area of the interiors was devoted to the posts to support the upper parts.

- Frame structure: The extension of the post and beam has produced frame structure nowadays. New materials have made it more usable and commonplace. Many terms are used, such as concrete frame structure, steel frame structure, wood-frame structure...etc. which they are all about the concept of beam and column. This structure has a limited span of creation. Interior spaces of this structure have flexibility inside the frame structure, achieving free plan concept, without freedom in exceeding this frame.

- Bearing wall: in this structural system, upper loads, all kinds of loads, are transferring via vertical components, which are walls. Here walls are not only separators but the support of the roofs and loads. In loadbearing walls, lintels also form the structure over the opened areas such as doors, windows, or other opening ways into the walls. Interiors of this system always have a strong sense of enclosure. Spans of spaces are limited. Also, the form is limited (generally squares and rectangular shapes) because of the limited capacity of the structure system. That is why this system is commonly used in horizontal residential units. 
- Arch: arch is a curved structure that can make spaces without additional support. It has many types and can be made from different building materials. From the very beginning of using arches, the used materials were mostly stones and bricks. After developing technology, other materials as steel and concrete participated, according to Architypes Structures (which is a website by some experts in design and construction). Arches have a great potential in creating possible interior spaces with the least of used materials. Also, the interior space is more flexible in use, as arches do not have internal supports. Using arches in a building gives human attention, especially when it is repeated, also gives the sense of direction.

- Vault: this structure is similar to an arch, but it is an unbroken series of arches without rupturing. It means that the vault can be seen as a single element that curves to both sides. It has several sorts with different shapes and forms. Vault considers as a robust structure system that can carry loads up to a high limit. Materials of the vault are the same as used in building arches. The interior space produced by the vault has a strong direction and an angle from the top of the vault.

- Dome: can be defined as a rotated arc around a circle, giving it a superpotential load-bearing. It can devote a huge space without any additional support. Domes have wide usage nowadays, especially in religious buildings, to show the dominance by the form and make the importance of a specific part of the building. Pantheon dome is the oldest built dome that changed the human attitude towards a structure that provided that huge space. Dome spaces have no back, side and front except a direction towards its centre. In interiors, human perceives a gathering and circulating sense. There is an allusion between the outside appearance of domes and inside spaces, as interior spaces look much bigger.

- Truss: "Trusses are triangular or pyramidal shapes used in the structure of buildings to make them more stable than structural components with 90-degree angles could. Bridges, platforms, towers, and houses are common types of truss structures" [4]. Trusses have a strong ability in making huge spaces. Either these spaces seem to be very complex (if it is not covered) in view due to the components of the truss. These membranes tell us something about technology. So that, a mega space will produce which is unhuman. However, this space may have flexibility in use.

- Shell: "the term "shell" is used to describe the structures which possess strength and rigidity due to its thin, natural and curved form such as the shell of an egg, a nut, human skull, and shell of tortoise" [5]. So its strength and durability belong to the shapes taken from nature as they are thin and strong. Many materials could be used to make shell structures nowadays, which they become the structure and cover. Spaces produced by this system are self-supported, and human feels nature in its interiors. Huge spans can be achieved for multiple purposes. Many desired shapes and forms can be designed as it is available in nature.

- Freeform structure: due to technological developments and software programs, a new form of structure has been invented that does not obey a specific known system or is created by combining more than a 
system. These new concepts are visualised in the real world and are called free form structures. Most of the time, there are philosophical or monumental ideas behind these forms. That is why unrealistic proportions can be seen, and humans perceive some futuristic emotions when thinking about them. Some of the forms are exotic, just as they borrowed in other planets.

- Pneumatic: Agrawal [6] explains the origin of Pneumatic structures as "The word pneumatic is derived from the Greek word 'pneuma' meaning breathe of air thus these are the structure which is supported by air". So it is a membrane that is filled with air to take shape. It has unbelievable ability in creating interior spaces without any supports inside. Its lightweight, which is a maximum of $3 \mathrm{~kg} / \mathrm{m} 2$, gives it a workability performance. Instead, it is malleable in fulfilling some forms which may be challenging to obtain by other structures. Pneumatics are easy to erect, economy, safe during collapses or events, also rich in supplying natural lighting to inside.

- Tensile structure: This type of structure depends on the tension member components rather than compression ones. For that, cables, tents, and prestressed members are mainly used. The main idea of this structure has come from nomadic tents, which easily used tents to own a suitable space, useable, movable, and friendly to the environment. After technological progression, this idea took a new place in architecture which is called tensile structure. The old system was superseded endorsed by new materials. Nowadays, applications of this structure are commonplace. As the spaces seem to be hanged visually, also we feel the structure is light and flexible.

Table 1. Types of structure in architecture

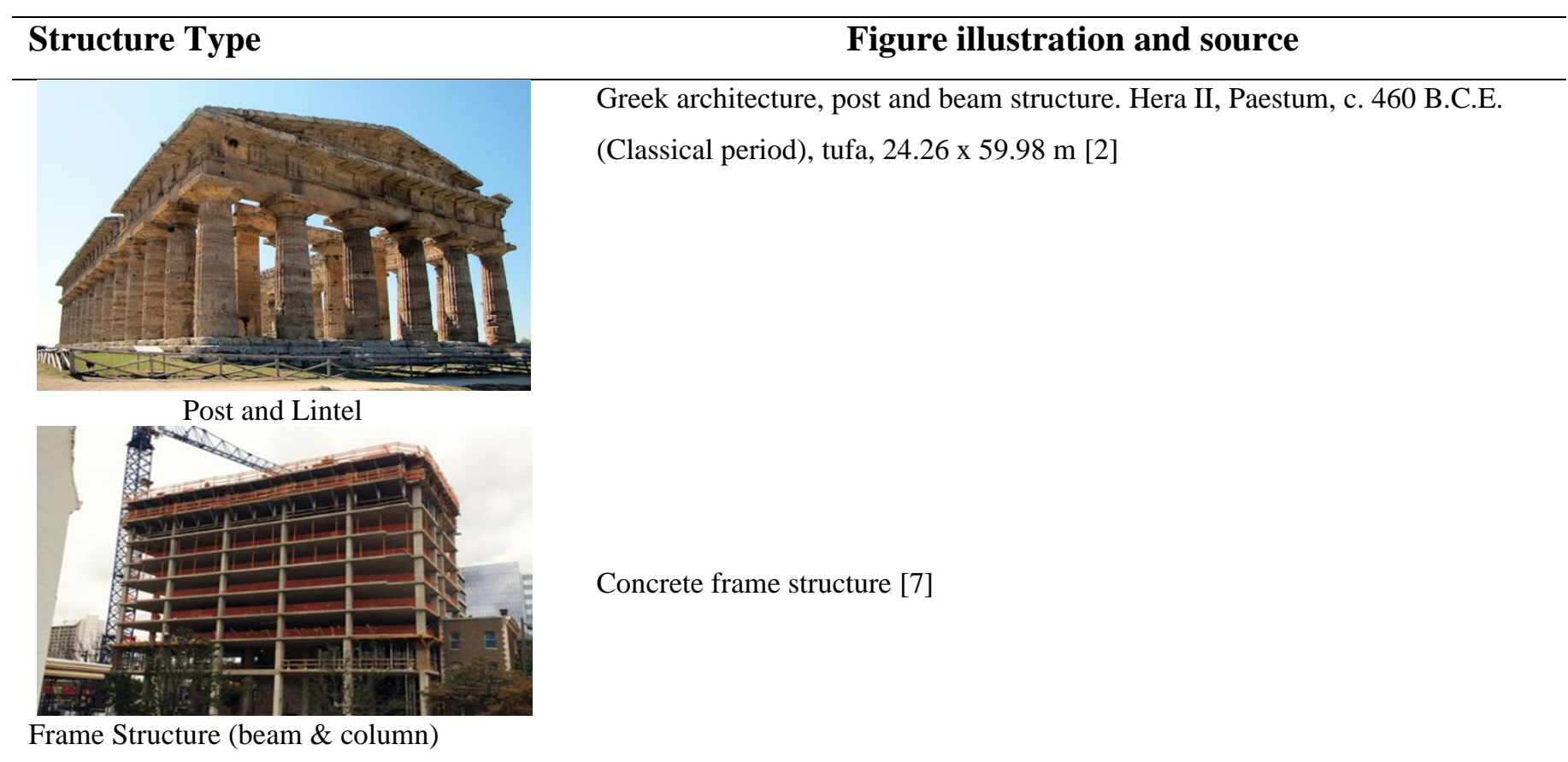




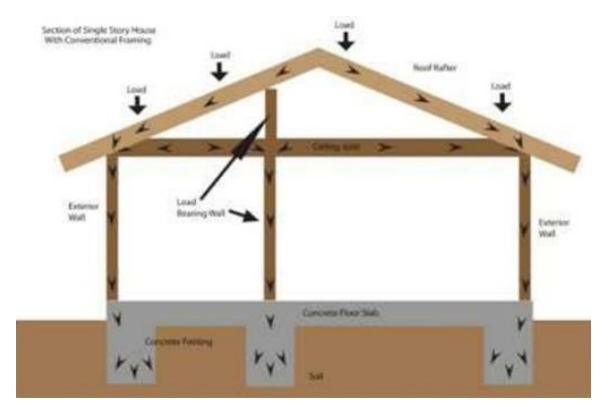

Load-bearing structure

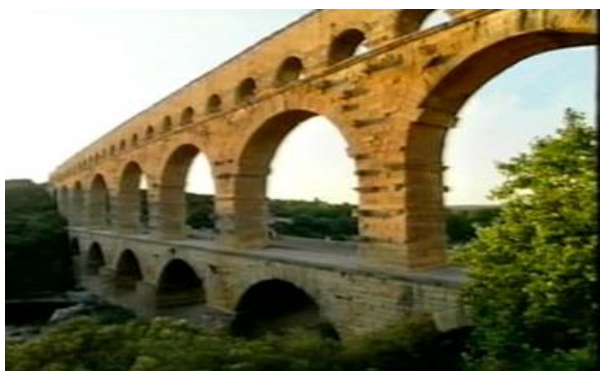

Arch
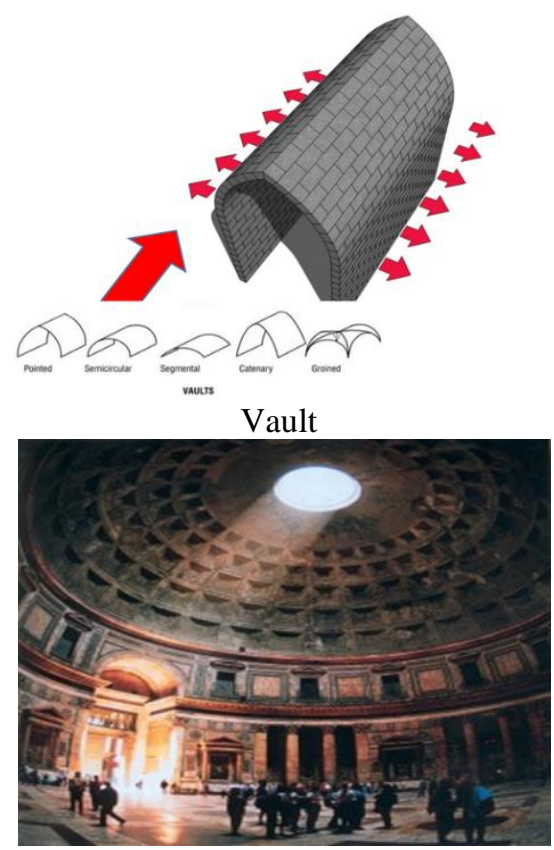

Dome
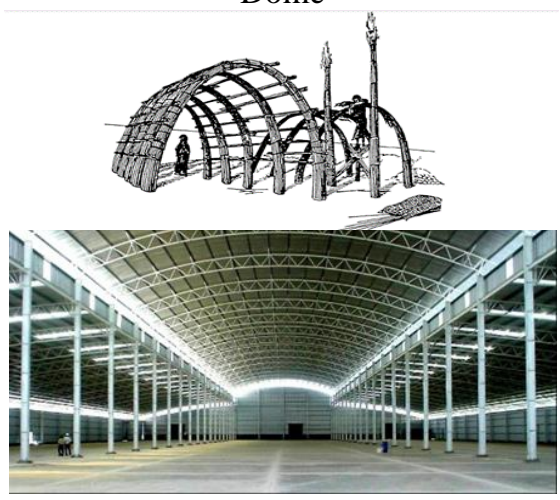

Truss
An example of a load-bearing structure and transferring loads [8]

POND DE GARD: Roman architecture, France [9]

Vault types and directions of space

Pantheon dome [10]

(1) Structure invented from early stages [11]

(2) An example of using truss structure [5] 


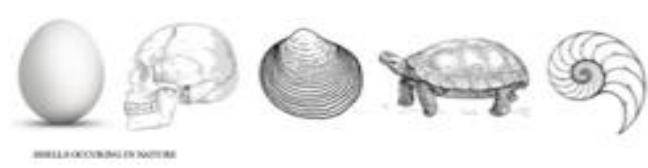

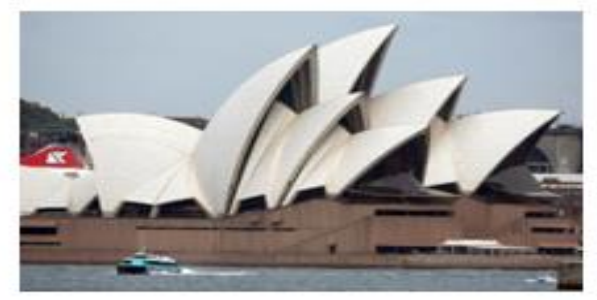

Shells

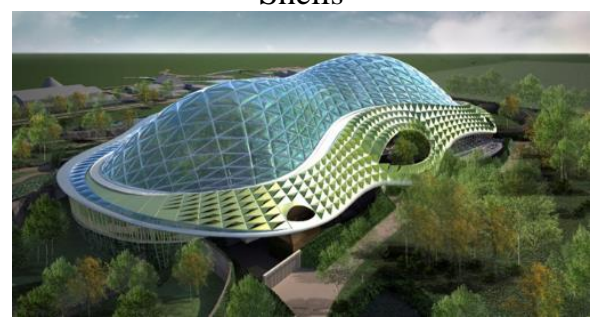

Freeform structure

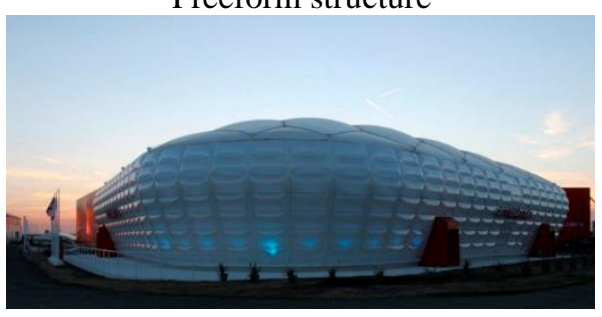

Pneumatic structure

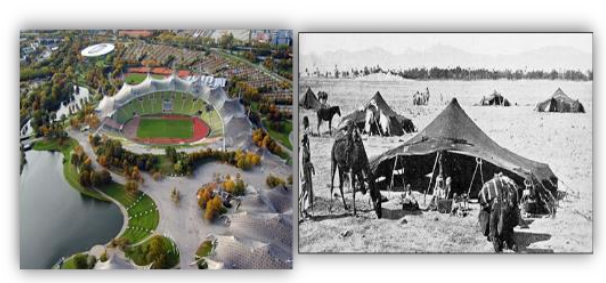

Tensile structure
(1) Shells available in nature [5].

(2) Sydney Opera, a shell structure system [12]

Chester Zoo; an example of free form structure [13]

\section{A Pneumatic structure example [14]}

Nomadic tents and Olympic stadium in Munich

\section{Materials and Methods}

Through applying a qualitative research methodology which is an analytical method that tries to survey the information available on structural systems from an architectural viewpoint, as well as a case study, has been taken to visualise what has been achieved in the literature review to know how the current structure in the case study has changed/gave the identity of these spaces. The colour building of the architecture department, more focused, the A10 studio has been taken to analyse.

\section{Results and Discussions}

\subsection{Case study - Color building in Architecture faculty at EMU/Cyprus.}

As illustrating the effects of structures on the identity of interior spaces, the colour building of the faculty of architecture in EMU-Cyprus has been taken as a case study. The building has an obvious structure which is a concrete frame structure. This structure has affected the definition and degree of the boundary of interior 
spaces by dividing the spaces and limiting also placing doors and windows according to the existing structures' limits. Also, to further observation, one of the studios is focused on A10 on the first floor. To know how this frame structure impacts human perception because "We do not merely exist in a physical environment- we interact with it, posit it with significance and derive important meaning from it. The aesthetics cannot be absent from our built forms and just like the importance of a defined space...” [1].

These effects of the structure, which are commonly visuals, have changed the space's real sense. Most people give visual quality more important than other aspects of their surroundings $[1,15]$.

What is vital in this research is understanding the identity of this studio under the light of the structure since "architectural space identity depends on its structure and the function of the structure and geometry are the factors of space design thus the interaction of space and structure is necessary for creating human space"[16].

\section{Analysis of the building}

- The structure of the building is frame structure 'Concrete frame'.

- The geometry of the building: it consists of rectangular shapes representing the shape of the structure. The main shape is a rectangle, while other rectangular shapes are extruded and connected to it.

- The structure gave the building a kind of compacted form. The building has a semi-centralised organisation around the courtyard. The courtyard is continuous from the ground to the roof's final layer, where there is covered by glass skin. Its explicit shape is an intact rectangle, and its position in the centre and its floating into every floor increases the importance of the courtyard. These things are participating in making the courtyard a gathering space and also an inward-looking.

- The sense of closure is obvious because of having the floor, ceiling and boundary walls.

- The studio has a rectangular shape that has a linear path. It is easy to connect to adjacent spaces.

- It has a defined ceiling which is covered all the area. Nevertheless, it is divided by the structure ribs.

- Its ceiling is relatively suitable in height since the hall is huge.

- The structure by dividing the ceiling and walls has created several rectangular shapes, by a modular system in design, which juxtaposed to each other. This is encouraging the definition of space. This subdivision increases the visual focal points, angles and corners. This will become another point in which the structure caused a better visual definition for the space.

- The structural members have given the space a depth, which can be observed when standing at both ends of the hall. 
- Having light on both sides, to outside and to the courtyard, assures the connectivity of the space to in/outside.

- The structure restricted the shape, height, and width of the windows and the doors' height linked to the bottom of the concrete beams. These windows made the space be represented bigger than its actual scale. Also, these tall doors have broken the continuation of the wall, which is reduced the identity.

Table 2. Illustraions of the case study

Case study visuals

(1)

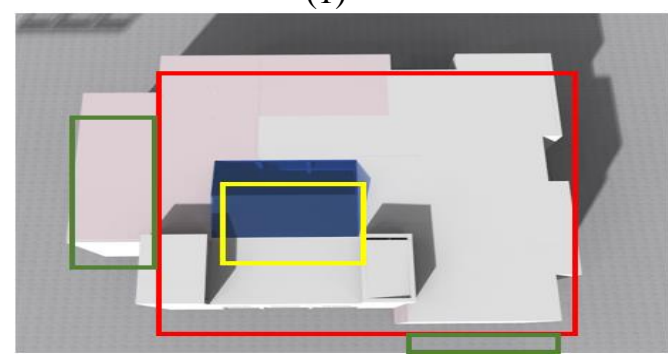

(2)

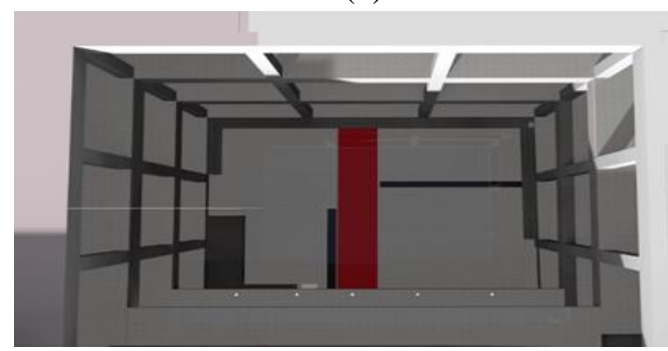

(3)

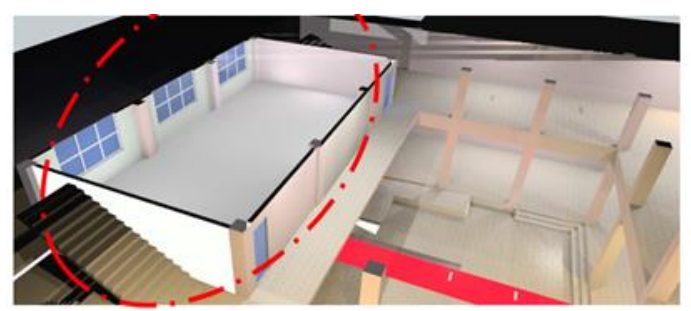

(4)

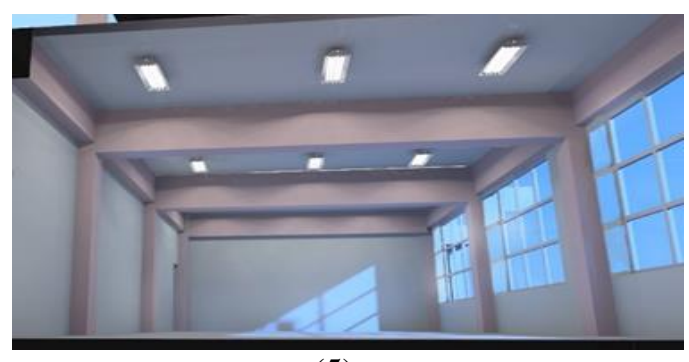

(5)

\section{Illustrations}

Concrete frame of Color Building

Geometrical shape of the color building

The main courtyard

The A10 studio

The A10 studio cross section 


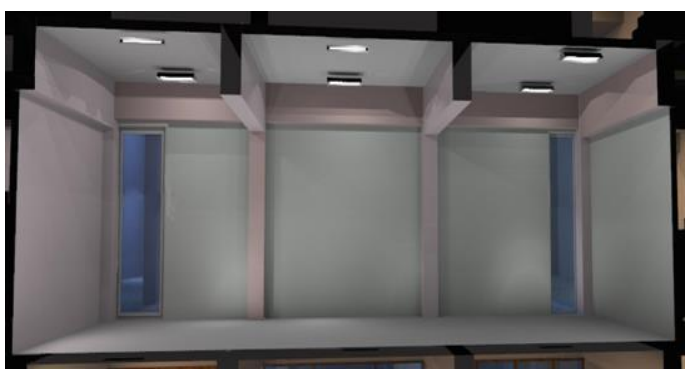

The A10 studio cross section 2

(6)

As from the case study, colour building-A10 Studio, held by a frame concrete structure, has given some specific identities to the studio space. Such as visual compartmentalisation of the walls and ceilings. This feature makes us perceive the space more defined, which the modularity of the structure created several modular shapes next to each other.

The structure regulated the size, height and width, of the windows. Beams and columns on three sides frame windows. Also, the height of the doors is limited by beams.

Extruding down the beams makes the space seem less high; also, relatively with the dimensions of the space is seen visually comfortable.

\section{Conclusions}

Structure defines the interior spaces. That is why different structural systems give the interiors different identities as vaulted structures give directions to the spaces, while domes do not have any side and back direction but a direction to the top. Also, domes' interiors are kind of stable and circulating. Frame structures compact the spaces they produce. At the same time, these spaces have a free plan character. Because inside the frame, the spaces can be separated by partitions as be desired accordingly. Structural designers attempt to design frame structures in a modular system. This modular system affects the spaces in that the subdivision of spaces proliferates the visual point focuses such as angles and corners. These characters of spaces cause to be perceived more defined.

Declaration of Competing Interest: The authors declare that they have no known competing of interest.

\section{References}

[1] P. S. Perolini, "Interior spaces and the layers of meaning," Design Principles Practices-An International Journal, pp. 5-6, 2011.

[2] J. L. Ambler. An introduction to ancient Roman architecture [Online]. Available: http://smarthistory.org/roman-architecture/

[3] D. J. Sporre, Reality through the arts. Prentice Hall, 1991.

[4] C. B. Fox. (2016). What Is Truss Structure? Available: https://www.infobloom.com/what-is-truss-structure.htm 
[5] URL-1. (2010, May 15, 2017). Shell structures. Available: https://www.slideshare.net/shwetamodi23/shell-structuresadvanced-building-construction?from_action=save

[6] A. A. Agrawal, "Pneumatic structure contemporary technology," Accessed on: May 26, 2016Available:

https://www.academia.edu/2393736/pneumatic_structure_technology?auto=download

[7] URL-2. (2016). Carson Concrete Corporation. Available: http://carsonconcrete.net/main.php

[8] Gregvancom, "Load Bearing Wall Framing Basics - Structural Engineering and Home Building Part One," ed, 2013.

[9] V. Ryan. (2009, May 20, 2016). Stone arch bridge. Available: https://www.technologystudent.com/struct1/arch1.htm

[10] Soudip. (2014, May 25, 2016). Pantheon Historical Facts and Pictures. Available: https://www.thehistoryhub.com/pantheonfacts-pictures.htm

[11] C. Schrein. (2016). The Domesticated Hominin. Available: https://www.sapiens.org/column/animalia/human-ancestors-anddomestication/

[12] A. Clennell. (2010, June 20, 2017). \$130m to save Sydney Opera House from closure. Available: https://www.news.com.au/national/m-to-save-sydney-opera-house-from-closure/newsstory/aa76ad754c5f6b444a5aa52321a55cc0

[13] A. Lysik. (2012). Design my world. Available: http://annalysik.blogspot.com/2013/02/geodesic-domes-\%20structuresgridshels.html

[14] S. Bartal, P. Brubaker, and S. Cruz. (2015). AE 390 Pnuematic Structural System. Available: https://sites.google.com/site/ae390pneumaticstructuralsystem/

[15] J. L. Nasar, "Visual quality by design," 2008: ASID.

[16] M. Azizi and Z. Torabi, "The role of structure in creating architectural space," Current World Environment, vol. 10, no. Special Issue, p. 131, 2015. 